\title{
The evaluation and management of patients with syncope: case report and overview of 2017 ACC/AHA/HRS Guidelines
} Dejan Kojic ${ }^{1}$, Nebojsa Mujovic ${ }^{2,3}$

${ }^{1}$ Institute for Cardiovascular Diseases Dedinje, Belgrade, Serbia, ${ }^{2}$ Cardiology Department, Clinical Centre of Serbia, Belgrade, Serbia, ${ }^{3}$ School of Medicine, University of Belgrade, Belgrade, Serbia

Abstract

Introduction: Syncope is frequent symptom with different etiologies. Reported prevalence in general population was as high as $41 \%$. If the etiology of syncope remain undefined after initial evaluation then an additional diagnostic tests are indicated based on clinical assessment.

Case report: We present a 57 year old female with ischemic cardiomyopathy with mildly reduced systolic left ventricular function who presented with recurrent syncope. The diagnosis of sustained monomorphic ventricular tachycardia was confirmed after insertion of implantable cardiac rhythm monitor and implantable cardioverter-defibrillator was implanted.

Conclusion: Treatment of syncope due to cardiac causes depends on the specific cause and should be based on relevant guidelines. Sometimes clinical guidelines miss selected patient groups due to lack of data, and in these cases clinical judgement is the most important part of decision making.

Kew words syncope, implantable cardiac rhythm monitor, ventricular tachycardia

\section{Introduction}

yncope is a sudden and temporary loss of consciousness and postural tone, with spontaneous recovery. ${ }^{1}$ It is an important clinical issue, accounting for up to $6 \%$ of hospital admissions. ${ }^{2} \mathrm{Ba}$ sed on clinical setting and etiology, a syncope is classified to neurally-mediated (60\%), orthostatic (15\%), syncope due to cardiac arrhythmia (10\%) and structural heart disease $(5 \%) .{ }^{3}$ In patients with cardiac syncope the risk of death is more than twofold increased. ${ }^{1}$ Several clinical factors for risk stratification in patients with syncope were proposed. ${ }^{1-3}$ Patients with history of syncope on exertion or palpitation, ECG abnormalities (such as bundle brunch block, pre-excitation, myocardial scar etc.) or family history of sudden cardiac death as well as older patients with severe structural heart or coronary disease are at high risk for overall fatality and sudden cardiac death. ${ }^{1-3}$ Although current ESC Guidelines for the management of patients with ventricular arrhythmias and the prevention of sudden cardiac death recommend an implantable cardioverter defibrillator (ICD) implantation in post-infarction patients with significantly reduced left ventricular ejection fraction (LVEF) $<40 \%$ for primary prevention of SCD, an optimal risk stratification for SCD in patients with chronic coronary disease and preserved systolic LV function is less well defined. ${ }^{4}$ Herein, we report a case of syncope due to monomorphic ventricular tachycardia (VT) in a patient with remote myocardial infarction and mildly reduced LVEF.

\section{Case report}

A 57-old woman was admitted to the Cardiology Department of Clinical Centre of Serbia due to recurrent syncope, occurring approximately five years after an acute inferior wall myocardial infarction (MI) with ST elevation. She was treated for hyperlipidemia and hypertension with beta-blocker (bisoprolol $5 \mathrm{mg}$ ), statin (atorvastatin $20 \mathrm{mg}$ ) and aspirin (100 mg daily). On examination after admission, heart sounds were normal, systolic blood pressure was $120 \mathrm{mmHg}$ and there were no signs of congestive heart failure or peripheral vascular disease. Twelve-lead ECG showed normal sinus rhythm 70 bpm with old inferior myocardial scar (Figure 1). Twenty four hour Holter-monitoring demonstrated stable sinus rhythm with no ventricular or supraventricular arrhythmias. An echocardiogram showed hypokinesia to akinesia of LV inferior and posterior wall and overall EF was estimated to 45-50\%. Coronary angiography revealed chronic occlusion of distal circumflex artery with non-significant stenosis of proximal part of left anterior descending coronary artery. The patient was referred to invasive electrophysiology study (EPS). However, using the standard ventricular tachycardia (VT) EP testing, consisting of programmed stimulation with 3 extra-stimuli $\left(\mathrm{S}_{1} \mathrm{~S}_{2} \mathrm{~S}_{3}\right)$ and burst pacing from right ventricular apex, sustained VT or ventricular fibrillation (VF) were not induced. Due to high clinical suspicion for ventricular tachyarrythmias as a cause of syncope, amiodarone therapy was started before discharge and according to proposed algorithm for evaluation of pati- 


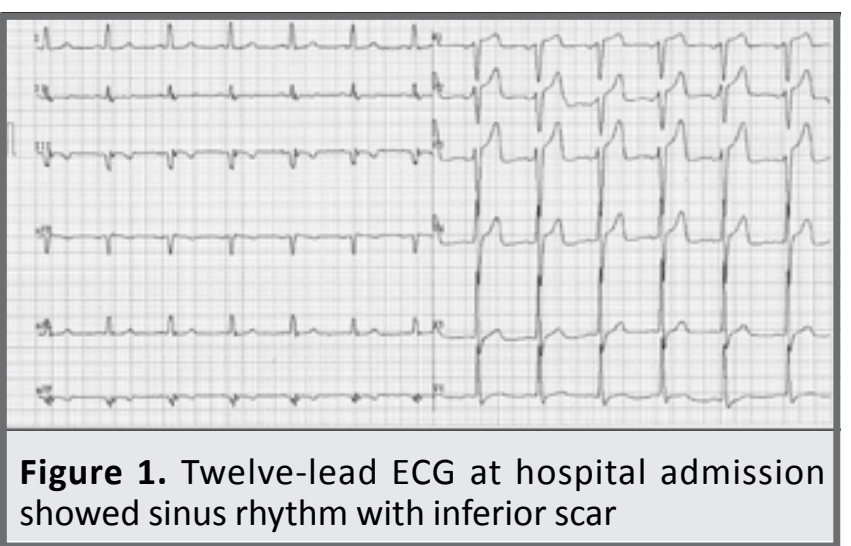

ents with unexplained syncope ${ }^{5}$ an implantable loop recorder (ILR, Reveal DX 9528, Medtronic) was inserted. After 21 months of clinical follow-up, interrogation of ILR revealed paroxysmal and sustained monomorphic VT of $270 \mathrm{bpm}$ (Figure 2) accompanied with chest pain and near- syncope episode. Immediately, she undergone an ICD implantation. After the 2 years post implantation, the patient experienced the first appropriate and successful ICD shock for fast VT occurrence.

\section{Discussion}

Our patient with syncope and coronary artery disease (CAD) was a high risk patient. However, this specific group of patients with previous $\mathrm{MI}$ and mildly reduced LVEF were not included in large randomized ICD clinical trials so clear recommendations are lacking. An electrophysiological study (EPS) with programmed ventricular stimulation (PVS) had been used to assess the inducibility of VT, evaluate loss of consciousness and assess the indications for ICD therapy.

However the diagnostic yield varies greatly with the selected patient populations. ${ }^{20}$ In CAD it may reach $50 \%$. Syncope associated with heart disease and reduced ejection fraction has high recurrence and mortality rates, even when EPS results are negative. ${ }^{21}$ Since the likelihood of arrhythmic cause of syncope was high and the event was relatively infrequent we decided to insert an implantable loop recorder. After 21 months of follow up we made a diagnosis of VT and the patient had undergone an ICD implantation. Treatment of syncope due to cardiac causes depends on the specific cause and should be based on relevant guidelines. However sometimes clinical guidelines miss selected patient groups due to lack of data, and in these cases clinical judgement is the most important part of decision making.

\section{Overview of 2017 ACC/AHA/HRS Guideline for Patients With Syncope}

Clinical practice guidelines are based on systematic methods to evaluate and classify evidence, and provide a cornerstone for quality cardiovascular care. Recently, for the first time, American Collegeof Cardiology (ACC), American Heart Association (AHA) and HeartRhythm Society (HRS) have been published Guideline for the evaluation and management of patients with syncope. The goals ofthe present guideline were to define syncope as a symp-

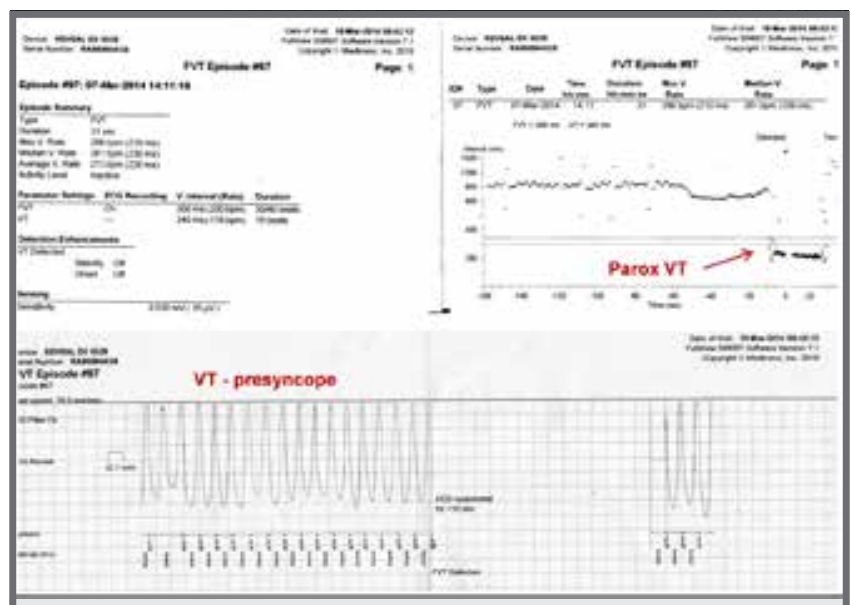

Figure 2. ECG tracing showing paroxysmal fast sustained monomorphic VT detected by the implanted loop recorder

tom, with different causes, in different populations and circumstances; to provide guidance and recommendations on the evaluation and management of patients with suspected syncope in the context of different clinical settings, specific causes, or selected circumstances; and to identify key areas in which knowledge is lacking. ${ }^{6}$

\section{Definition of syncope}

These guidelines define syncope as "a symptom that presents with an abrupt, transient, complete loss of consciousness, associated with inability to maintain postural tone, with rapid and spontaneous recovery" with cerebral hypoperfusion as the presumed mechanism. ${ }^{6}$ Furthermore, "there should not be clinical features of other nonsyncope causes of loss of consciousness, such as seizure, antecedent head trauma, or apparent loss of consciousness (that is, pseudosyncope)". ${ }^{6}$ Studies of syncope report prevalence rates as high as $41 \%$, withrecurrent syncope occurring in $13.5 \%{ }^{7}$

\section{Initial evaluation}

An initial evaluation of syncope should start with detailed history, clinical examination and 12 lead electrocardiogram (ECG) (Class I). Major categories of syncope include neutrally mediated (reflex) syncope (vasovagal, situational, and carotid sinus hypersensitivity), orthostatic hypotension, and cardiac syncope .Certain characteristics may help identify types of syncope based on clinical presentation.For example older age, known ischemic or structural heart disease, previous arrhythmias, palpitations before syncope or sudden loss of consciousness without prodrome, syncope during exertion or in the supine position, family history of inheritabile conditions or premature sudden cardiac death, are usually associated with cardiac causes of syncope. Younger age, no known cardiac disease, syncope in standing position or in postural changes, presence of prodrome or specific triggers, and frequent recurrence of syncope with similar characteristics, are more often associated with noncardiac causes of syncope. 


\section{Risk stratification should be part of initial evaluation}

Obtaining a detailed history is crucial to understanding both the etiology of the syncopal eventand determining which patients are at high risk for adverse outcomes. New guidelines recommend assessment for the short- (up to 30 days after syncope) and long-term (up to 12 months of follow-up) morbidity and mortality risk of syncope, considering history, physical examination, and laboratory studies.

\section{Hospital evaluation and treatment}

Hospital evaluation and treatment are recommended for patients presenting with syncope who have a serious medical condition potentially relevant to the cause of syncope identified during initial evaluation. Serious medical conditions that might warrant consideration of further evaluation and therapy in a hospital setting can be arrhythmic (i.e sustained or symptomatic VT, symptomatic conduction system disease or Mobitz II or thirddegree heart block, symptomatic bradycardia or sinus pauses not related to neurally mediated syncope, symptomatic supraventricular tachycardia, pacemaker/ICD malfunction, inheritable cardiovascular conditions predisposing to arrhythmias), cardiac/vascular nonarrhythmic (i.e cardiac ischemia, severe aortic stenosis, cardiac tamponade, hypertrophic cardiomyopathy, severe prosthetic valve dysfunction, pulmonaryembolism, aortic dissection, acute HF, moderate-severe LV dysfunction), and noncardiac (i.e severe anemia/gastrointestinal bleeding, major traumatic injury due to syncope, and persistent vital sign abnormalities).

\section{Additional evaluation}

If the cause of syncope is not clear after initial evaluation then additional evaluation is indicated. A broadbased use of additional testing is costly and often ineffective. This guidelines provides recommendations for the most appropriate use of additional testing for syncope evaluation. Routine and comprehensive laboratory testing is not useful in the evaluation of patients with syncope. (Class III: No Benefit).

Routine cardiac imaging is not useful unless cardiac etiology is suspected on the basis of an initial evaluation, including history, physical examination, or ECG (Class III: No Benefit).

Transthoracic echocardiography can be useful in selected patients presenting with syncope if structural heart disease is suspected (Class Ila). Specific diagnostic tests can be useful in selected patient groups (exercise stress testing, cardiac rhythm monitoring, electrophysiological study, tilt- table testing) (Class Ila). Importantly, many patients undergo extensive neurological investigation after an uncomplicated syncope event, despite the absence of neurological features on history or examination. The evidence suggests that routine neurological testing is of very limited value in the context of syncope evaluation and management; the diagnostic yield is low, with very high cost per diagnosis. ${ }^{1,8-19}$ Consequently, ma- gnetic resonance imaging (MRI) and computed tomography (CT) of the head as well as carotid artery imaging are not recommended in the routine evaluation of patients with syncope in the absence of focal neurological findings or head injury that support further evaluation . Also rutine electroencephalography recording is not recommended in the absence of neurological features suggestive of a seizure (Class III: No Benefit).

\section{Management}

\section{Management of cardiovascular conditions}

In general, treatment strategies for cardiac causes od syncope including arrhythmic and structural conditions should be based on the relevant ACC/AHA Guidelines. This is so called guideline-directed management and therapy (GDMT). Comprehensive guidelines exist for diagnosis and management of many of these conditions, including sections on syncope.

\section{Management of reflex conditions}

\section{Vasovagal Syncope (VVS)}

Vasovagal syncope is the most common cause of syncope. ${ }^{3}$ Effectiveness of drug therapy is modest. ${ }^{5}$ Patient education on the diagnosis and prognosis is recommended (Class I). Physical counter-pressure maneuvers can be useful in patients with VVS who have a sufficiently long prodromal period (Class Ila). Midodrine, an alphaadrenergic vasoconstricting agent is reasonable in patients with recurrent VVS with no history of hypertension, $\mathrm{HF}$, or urinaryretention (Class Ila).Dual-chamber pacing might be reasonable in a select population of patients 40 years of age or older with recurrent VVS and prolonged spontaneous pauses (Class IIb).

\section{Carotid Sinus Syndrome}

Permanent cardiac pacing is reasonable in patients with carotid sinus syndrome that is cardioinhibitory or mixed (Class Ila).

\section{Orthostatic hypotension (OH)}

Syncope suspected of $\mathrm{OH}$ can be mediated by neurogenic conditions, dehydration, or drugs. Fluid resuscitation by acute water ingestion or intravenous infusion isrecommended for occasional, temporary relief in patients with neurogenic $\mathrm{OH}$ or dehydration (Class I). Reducing or withdrawing medications that may cause hypotension can be beneficial in selected patients with syncope (Class Ila).

\section{References}

1. Soteriades ES, Evans JC, Larson MG, et al. Incidence and prognosis of syncope. N Engl J Med 2002;347:878-85.

2. Blanc JJ, L'Her C, Touiza A, Garo B, L'Her E, Mansourati J. Prospective evaluation and outcome of patients admitted for syncope over a 1 year period. Eur Heart J 2002;23:815-20.

3. Sutton R. Clinical classification of syncope. Prog Cardiovasc Dis. 2013;55:339-44.

4. Priori SG, Blomström-Lundqvist C, Mazzanti A, et al. 2015 ESC Guidelines for the management of patients with ventricular arrhythmias and the prevention of sudden cardiac death: The 
Task Force for the Management of Patients with Ventricular Arrhythmias and the Prevention of Sudden Cardiac Death of the European Society of Cardiology (ESC)Endorsed by: Association for European Paediatric and Congenital Cardiology (AEPC). Europace. 2015;17:1601-87.

5. Brignole M. Diagnosis and treatment of syncope. Heart. 2007; 9:130-6.

6. Shen W-K et al. 2017 ACC/AHA/HRS guideline for the evaluation and management of patients with syncope. J Am Coll Cardiol. 2017 Aug 1;70(5):e39-e110

7. Khera S, Palaniswamy C, Aronow WS, et al. Predictors of mortality, rehospitalization for syncope, and cardiac syncope in 352 consecutive elderly patients with syncope. J Am Med Dir Assoc. 2013;14:326-30.

8. Kapoor WN, Karpf M, Wieand S, et al. A prospective evaluation and follow-up of patients with syncope. N Engl J Med. 1983; 309: 197-204.,

9. Mendu ML, McAvay G, Lampert R, et al. Yield of diagnostic tests in evaluating syncopal episodes in older patients. Arch Intern Med. 2009; 169:1299-305.

10. Johnson PC, Ammar H, Zohdy W, et al. Yield of diagnostic tests and its impact on cost in adult patients with syncope presenting to a community hospital. South Med J. 2014; 107:707-14.

11. Al-Nsoor NM, Mhearat AS. Brain computed tomography in patients with syncope. Neurosciences (Riyadh). 2010; 15:105-9.

12. Giglio P, Bednarczyk EM, Weiss K, et al. Syncope and head CT scans in the emergency department. Emerg Radiol. 2005; 12:44-6.
13. Goyal N, Donnino MW, Vachhani R, et al. The utility of head computed tomography in the emergency department evaluation of syncope. Intern Emerg Med. 2006; 1:148-50.

14. Abubakr A, Wambacq I. The diagnostic value of EEGs in patients with syncope. Epilepsy Behav. 2005; 6:433-4.

15. Poliquin-Lasnier L, Moore FGA. EEG in suspected syncope: do EEGs ordered by neurologists give a higher yield? Can J Neurol Sci. 2009; 36:769-73.

16. Kang GH, Oh JH, Kim JS, et al. Diagnostic patterns in the evaluation of patients presenting with syncope at the emergency or outpatient department. Yonsei Med J. 2012; 53:517-23.

17. Mecarelli O, Pulitano P, Vicenzini E, et al. Observations on EEG patterns in neurally-mediated syncope: an inspective and quantitative study. Neurophysiol Clin. 2004; 34:203-7.

18. Mitsunaga MM, Yoon HC. Journal Club: Head CT scans in the emergency department for syncope and dizziness. AJR Am J Roentgenol. 2015; 204:24-8.

19. Sclafani JJ, My J, Zacher LL, et al. Intensive education on evidencebased evaluation of syncope increases sudden death risk stratification but fails to reduce use of neuroimaging. Arch Intern Med. 2010; 170:1150-4.

20. Denes P, Uretz E, Ezri MD, Borbola J. Clinical predictors of electrophysiologic findings in patients with syncope of unknown origin. Arch Intern Med 1988;148:1922-1928.

21 Middlekauff HR, Stevenson WG, Stevenson LW, Saxon LA. Syncope in advancedheart failure: high risk of sudden death regardless of origin of syncope. J Am Coll Cardiol 1993;21:110-116.

\section{Sažetak \\ Evaluacija i lečenje pacijenata sa sinkopom: prikaz slučaja i pregled ACC/AHA/HRS preporuka iz 2017}

Dejan Kojić1, Nebojša Mujović2,3

${ }^{1}$ Institut za kardiovaskularne bolesti Dedinje, Beograd, Srbija, ${ }^{2}$ Klinika za kardiologiju, Klinički centar Srbije, Beograd, Srbija, ${ }^{3}$ Medicinski fakultet, Univerzitet u Beogradu, Beograd, Srbija

Uvod: Sinkopa je čest simptom raznovrsne etiologije. Prevalenca u opštoj populaciji iznosi čak do $41 \%$. U koliko uzrok sinkope ostane nedefinisan nakon inicijalne evaluacije indikovani su dopunski dijagnostički testovi nakon kliničke procene.

Prikaz slučaja: Prikazujemo pacijentkinju starosti 57 godina sa ishemijskom kardiomiopatijom i blago sniženom sistolnom funkcijom leve komore sa kliničkom prezentacijom rekurentne sinkope. Dijagnoza dugotrajne monomorfne ventrikularne tahikardije je potvrđena nakon insercije implantabilnog monitora srčanog ritma, a nakon toga je ugrađen implantabilni kardioverter defibrilator.

Zaključak: Lečenje kardijalne sinkope zavisi od specifičnog uzroka i treba da bude zasnovano na relevantnim preporukama. Nekada kliničke preporuke ne pokrivaju određene grupe pacijenata zbog nedistatka dokaza iz kliničkih studija. U ovim slučajevima procena kliničara postaje najvažniji kriterijum za donošenje odluka.

Ključne reči: sinkopa, implatabilni monitor srčanog ritma, ventrikularna tahikardija 